\title{
Attenuation of Experimental Pain by Vibro-Tactile Stimulation in Patients with Chronic Local or Widespread Musculoskeletal Pain
}

\author{
Roland Staud, Michael E. Robinson, Casey T. Goldman, and Donald D. Price \\ University of Florida, Gainesville, Florida 32610
}

\section{Abstract}

Patients with chronic pain syndromes, like fibromyalgia (FM) complain of widespread pain and tenderness, as well as non-refreshing sleep, cognitive dysfunction, and negative mood. Several lines of evidence implicate abnormalities of central pain processing as contributors for chronic pain, including dysfunctional descending pain inhibition. One form of endogenous pain inhibition, diffuse noxious inhibitory controls (DNIC), has been found to be abnormal in some chronic pain patients and evidence exists for deficient spatial summation of pain, specifically in FM. Similar findings have been reported in patients with localized musculoskeletal pain (LMP) disorders, like neck and back pain. Whereas DNIC reduces pain through activation of nociceptive afferents, vibro-tactile pain inhibition involves innocuous A-beta fiber. To assess whether patients with localized or widespread pain disorders have dysfunctional A-beta related pain inhibition we enrolled 28 normal pain-free controls (NC), 29 FM patients, and 19 subjects with neck or back pain. All received $10 \mathrm{~s}$ sensitivity-adjusted noxious heat stimuli to the forearms as test stimuli. To assess endogenous analgesic mechanisms of study subjects, vibro-tactile conditioning stimuli were simultaneously applied with test stimuli either homotopically or heterotopically. Additionally, the effect of distraction on experimental pain was assessed. Homotopic vibro-tactile stimulation resulted in $40 \%$ heat pain reductions in all subject groups. Distraction did not seem to affect experimental pain ratings.

Conclusions-Vibro-tactile stimulation effectively recruited analgesic mechanisms not only in $\mathrm{NC}$ but also in patients with chronic musculoskeletal pain, including FM. Distraction did not seem to contribute to this analgesic effect.

\section{Keywords}

Analgesia; Fibromyalgia; Chronic pain; Facilitation; Inhibition; Vibration

\section{Introduction}

Chronic widespread pain (CWP) disorders, like fibromyalgia syndrome (FM) are characterized by pain and other clinical manifestations such as sleep disturbance, fatigue, negative affect, gastrointestinal symptoms, and headaches (Clauw 1995; Wolfe 1990). Although the pathogenesis of CWP is only incompletely understood (Vierck, Jr. 2006), increasing evidence points toward the important roles of abnormal peripheral (Staud et al., 2009; Staud et al., 2010) and central pain mechanisms (Desmeules et al., 2003; Staud 2009).

Corresponding author: Roland Staud, M.D., Department of Medicine University of Florida College of Medicine, Gainesville, FL 32610-0221, Telephone: (352) 273-5345, Fax: (352) 392-8483, staudr@ufl.edu.

Publisher's Disclaimer: This is a PDF file of an unedited manuscript that has been accepted for publication. As a service to our customers we are providing this early version of the manuscript. The manuscript will undergo copyediting, typesetting, and review of the resulting proof before it is published in its final citable form. Please note that during the production process errors may be discovered which could affect the content, and all legal disclaimers that apply to the journal pertain. 
Biochemical abnormalities in the cerebrospinal fluid (CSF) of some CWP patients, like FM include low levels of serotonin (5HT) and noradrenaline (NA) (Russell et al., 1992), high levels of substance P (Russell et al., 1994; Vaeroy et al., 1988) and of nerve growth factors (Giovengo et al., 1999) providing indirect evidence for abnormal central pain modulation. Abnormal levels of CSF neurotransmitters may also account for some of the symptoms experienced by many CWP patients such as sleep disturbance, fatigue, cognitive abnormalities, and depression. Moreover, reductions of 5HT and NA in the CSF seem to suggest dysfunction of the descending inhibitory systems (Lautenbacher and Rollman 1997) which may, at least in part, be responsible for the widespread pain of these patients.

Inadequate pain inhibition has been detected in FM patients but not in healthy control subjects (NC) during noxious counter-stimulation experiments (Kosek and Hansson 1997; Lautenbacher and Rollman 1997; de Souza et al., 2009). Similar findings have been reported in patients with localized musculoskeletal pain (LMP) disorders like osteoarthritis (OA) (Arendt-Nielsen et al., 2010). Dysfunctional central pain inhibition also appears to be responsible for abnormal spatial summation (Julien et al., 2005) and reduced pain habituation in FM patients (Montoya et al., 2006; Smith et al., 2008). Although pain inhibitory systems did not seem to be optimally recruited by spatial summation procedures in CWP patients, they were effective for chronic low back pain patients and NC (Julien et al., 2005). However, these studies used highly noxious counter-stimulation techniques, which may have produced a form of stress analgesia (Butler and Finn 2009; Carlton et al., 2004). Floor or ceiling effects in such studies may also have contributed to disparate results. Other groups using shorter and/or less intense stimuli have reported adequate DNIC (Lautenbacher et al., 2008; Staud et al., 2003) and normal spatial summation responses in CWP patients (Staud et al., 2004b). These controversial findings suggest that at least some pain-inhibitory mechanisms are normal in CWP. A mechanism yet to be tested is that of vibro-tactile analgesia which relies on high frequency stimulation of low threshold A-beta mechanoreceptors (e.g., Pacinian corpuscles), segmental dorsal horn mechanisms (Salter and Henry 1990a; Salter and Henry 1990b), and possibly mechanisms within the somatosensory cortex (Peltz et al., 2011) (Tommerdahl et al., 1999a; Tommerdahl et al., 2005). Vibrotactile analgesia is mechanistically very different from various forms of counter-stimulation that rely on stimulation of high threshold primary afferent neurons (e.g., DNIC and high intensity- low frequency TENS). Vibro-tactile stimulation of A-beta primary afferents produces potent inhibition of dorsal horn nociceptive neurons (Salter and Henry 1990a; Salter and Henry 1990b) and somatosensory cortical neurons in area 3B (Tommerdahl et al., 1999a). Thus we tested whether painless vibro-tactile conditioning stimuli would produce robust experimental pain reductions in CWP and LMP patients compared to NC.

\section{Methods}

\subsection{Study Participants}

Subjects were recruited from the local community and FM support groups, as FM seems to represent the extreme end of CWP. Informed consent was obtained from all participants and the study protocol conformed to the ethical guidelines of the 1975 Declaration of Helsinki.

The University of Florida Institutional Review Board approved the procedures and protocol for this study. Besides pain-free NC and FM subjects, participants with LMP, including neck or back pain were enrolled if they had chronic pain for at least 3 months. Prior to testing, all subjects underwent a clinical examination and were excluded from the study if they had abnormal findings unrelated to CWP or LMP, i.e. signs of neuropathy, acute physical injury, etc. Use of analgesics, including non-steroidal anti-inflammatory drugs (NSAID) and acetaminophen, was not allowed during the study. All subjects were asked to discontinue analgesics for the duration of five drug half-lives before testing, except narcotics which had to be stopped at least two weeks prior to study entry. Low dose muscle relaxants and/or 
antidepressants (i.e. amitriptyline $\leq 10 \mathrm{mg} /$ day) were permissible during the study for treatment of insomnia.

\subsection{Experimental Design}

All subjects received 4 sensitivity adjusted heat stimuli to each forearm in counterbalanced order during every experimental condition (baselines, homotopic, and heterotopic condition). Baseline ratings of sensitivity adjusted heat pulses were obtained from all subjects before and after homotopic and heterotopic conditions (Baseline 1 - Homotopic/ Heterotopic - Baseline 2 - Heterotopic/Homotopic - Baseline 3) to assess the stability of baseline heat pain ratings and to detect the occurrence of sensitization or habituation.

At the beginning of each experiment the study subjects were instructed that mild to moderately painful heat stimuli would be placed on different areas of their forearms for $10 \mathrm{~s}$ each. After each stimulus they were asked to rate the pain intensity of these stimuli using a mechanical visual analogue scale (VAS) (Price et al., 1994). In addition, a vibrating probe was placed either on the same forearm next to the heat stimulus or on the forearm opposite to the heat stimuli. All participants rated pain intensity at the end of each $10 \mathrm{~s}$ stimulus. Homotopic and heterotopic vibro-tactile stimuli were applied in counterbalanced order. The participants were not specifically asked to focus either on the conditioning or test stimuli during each experiment. However, in order to assess the contribution of distraction by vibrotactile analgesia, participants were asked after each run, by forced choice, to indicate which probe (heat or vibro-tactile probe) they focused their attention on during the experiment.

\subsection{Vibro-tactile Stimulation}

2.3.1 Bio-Thesiometer-An electronic Bio-Thesiometer (Biomedical Instrument Co., Ohio) was used for vibro-tactile stimuli. This instrument transmitted graded vibratory stimuli at a frequency of $100 \mathrm{~Hz}$ through a round foot plate (diameter $4 \mathrm{~cm}$ ) to the skin and deep tissues. This instrument was used for conditioning stimuli and to test vibratory thresholds of study subjects.

2.3.2 Vibratory Thresholds-For vibro-tactile thresholds a method - of limits approach was utilized on both forearms. The intensity of vibration was increased by $.01 \mathrm{~m} / \mathrm{s}^{2}$ from zero until the subjects detected the sensation. Subsequently the intensity of vibration was decreased in steps of $.01 \mathrm{~m} / \mathrm{s}^{2}$ until the sensation disappeared. The average of three repetitions was used to determine vibratory thresholds. For either homotopic or heterotopic conditioning stimuli, a constant stimulus intensity of $.23 \mathrm{~m} / \mathrm{s}^{2}$ was utilized.

2.3.3 Vibratory Stimuli-For testing of analgesic mechanisms 10 second vibro-tactile stimuli and heat stimuli were sequentially applied to the forearm of study subjects either in homotopic or heterotopic fashion. The heat probe was always applied to the skin before the vibrating probe. While the heat probe was kept at ambient skin temperature $\left(35^{\circ} \mathrm{C}\right)$ and before the probe temperature increased to target levels, the vibratory stimulator was placed on the skin. For homotopic stimuli the foot-plate of the bio-thesiometer was placed approximately $2 \mathrm{~cm}$ next to the Peltier heat probe on the forearm. For heterotopic stimuli the bio-thesiometer was pressed against one forearm while the test stimulus was applied to the opposite forearm at the same location.

\subsection{Ratings of Pain}

2.4.1 Ratings of Experimental Pain-A $15 \mathrm{~cm}$ mechanical VAS (0 - 10) was used for ratings of experimental pain during heat stimulation (Price and Harkins 1992). The scale was anchored on the left with "no pain at all" and on the right with "the most intense pain imaginable". 
2.4.2 Ratings of Somatic Pain-The same mechanical VAS $(0-10)$ used for experimental pain ratings was also utilized for ratings of somatic pain at the beginning and end of each experimental procedure. Although the NC subjects were required to be pain free at enrollment their somatic pain ratings were obtained before and after the testing session to capture possible new onset symptoms like back pain, headaches, etc. Prior to the experiments, all subjects completed a body pain diagram to identify whether they had any clinical pain in the test areas (forearms). Briefly, a mannequin drawing depicting the front and back of the human body was given to the study subjects to shade in painful body areas, as previously described in detail (Staud et al., 2004a).

\subsection{Heat Stimuli}

2.5.1 Thermal probe-A Peltier thermode with a contact surface of $3 \times 3 \mathrm{~cm}\left(9 \mathrm{~cm}^{2}\right)$ (TSA-2001, Medoc Advanced Medical Systems, Ramat Yishai, Israel) was used for the heat stimuli. For heat pain testing the preheated probe was brought into firm contact with the skin of the volar forearm for $10 \mathrm{~s}$.

2.5.2 Heat Stimuli-Experimental pain was elicited by $10 \mathrm{~s}$ sensitivity adjusted heat pulses to the volar surface of the forearm ispilateral and contralateral to the conditioning stimuli. In order to preferentially activate $\mathrm{C}$-fiber afferents the Peltier probe was programmed to increase from ambient baseline $\left(35^{\circ} \mathrm{C}\right)$ to target temperature in $8 \mathrm{~s}$. Afterwards, it remained at target temperature for $2 \mathrm{~s}$ for a total stimulus duration of $10 \mathrm{~s}$ Two areas of each volar forearm were marked, separated by $5 \mathrm{~cm}$. Four sensitivity adjusted $10 \mathrm{~s}$ heat pulses were applied to these areas in counterbalanced order. At the end of each 10 $\mathrm{s}$ heat stimulus the participants were immediately asked to rate the intensity of the experimental pain sensations using the VAS.

\subsubsection{Adjustment of Heat Stimuli to Each Subject's Pain Sensitivity-Pain} sensations from fixed heat stimuli vary as a function of each subject's peripheral and central sensitivity. Because this variability is frequently associated with "ceiling" or "floor" effects, we normalized individual heat pains by applying the unique heat stimuli necessary for forearm skin pain ratings of $4.0 \pm 0.5 \mathrm{VAS}$ units. This manipulation provided a measure of thermal pain sensitivity for each subject. To identify individual stimulus intensities associated with moderate heat pain ratings ( $4.0 \pm 0.5 \mathrm{VAS}$ units), each subject underwent several $10 \mathrm{~s}$ heat pain trials. Stimulus trains were initially comprised of $10 \mathrm{~s} 45^{\circ} \mathrm{C}$ heat stimuli. The temperature slowly increased from baseline to target temperature in $8 \mathrm{~s}$. After it reached target temperature it was maintained for $2 \mathrm{~s}$. If necessary, peak temperatures were raised or lowered during subsequent trials until subjects achieved maximal heat pain ratings of $4.0 \pm 0.5$ VAS units. This temperature was subsequently used for all heat pain experiments. Thus, these heat pain trials provided a standard condition which was designed to be very similar within and between subject groups.

\subsection{Distraction by Vibro-Tactile Stimuli}

In order to assess effects of distraction on experimental pain, all subjects were asked (by forced choice) after each experiment using conditioning stimuli whether they felt distracted by vibro-tactile stimulation. In addition, VAS ratings of distraction magnitude (0-10) were obtained at the same time. The VAS scale was limited on the left by no distraction at all and on the right by most distraction imaginable.

\subsection{Tender Point Testing}

Nine paired TPs as defined by the ACR Criteria (Wolfe et al., 1990) and two control points (at the center of the right forearm and the right thumbnail) were assessed by a trained 
investigator using a Wagner Dolorimeter (Force Measurement, Greenwich, CT). The rubber tip of the Dolorimeter was $1 \mathrm{~cm}$ in diameter. The Dolorimeter was placed on the examination site, and pressure was gradually increased by $1 \mathrm{~kg} / \mathrm{s}$. The subjects were instructed to report when the sensation at the examination site changed from pressure to pain. Pressure testing was stopped at that moment and the result recorded as positive (1) if maximal pressure was $\leq 4 \mathrm{~kg}$. If no pain was elicited at $\geq 4 \mathrm{~kg}$ the test result was recorded as negative (0).

\subsection{Statistical Analyses}

Statistical analyses were conducted using SPSS 17.0 software (SPSS, Inc., Chicago, IL). One-way ANOVAS were used for group comparisons of stimulus temperatures and their associated pain ratings. A series of mixed model ANOVAs for repeated measures was utilized to test experimental pain ratings for differences within and between conditions (homotopic - heterotopic) and groups (Alpha level <.05). When appropriate, statistically different means were decomposed using a series of simple contrasts (two-tailed).

\section{Results}

\subsection{Study Participants}

We enrolled $28 \mathrm{NC}$ subjects ( 25 female; 3 male), 29 FM subjects ( 24 female; 5 male), and 19 local musculoskeletal pain (LMP) subjects (15 female and 4 male) into the study. LMP subjects were comprised of 7 individuals with chronic neck pain and 12 individuals with chronic low back pain. During the study 4 subjects with FM and 1 subject with LMP took 10 $\mathrm{mg}$ cyclobenzaprine at night for treatment of insomnia. 1 FM subject took $25 \mathrm{mg}$ trazodone daily. The mean age (SD) of study participants was 30.0 (11.0), 38.4 (11.4), and 43.7 (15.6) for NC, FM, and LMP, respectively. A one-way ANOVA demonstrated a significant effect for age $(F(2)=6.2 ; p=.004)$. Post-hoc testing using Duncan's procedure identified NC as significantly younger compared to FM and LMP subjects ( $\mathrm{p}<.05)$. Pearson's product moment correlation, however, showed no significant effects of age on experimental pain ratings ( $p>.05)$. Average number of tender points (SD) was $3.1(0.2)$ for NC, 16.5 (1.7) for FM, and $10.6(0.9)$ for LMP subjects.

\subsection{Clinical Pain Ratings}

Overall clinical pain of NC was minimal (0.1 VAS units), whereas FM and LMP subjects rated their average (SD) pain as 4.3 (2.1) and 3.4 (2.7) VAS units, respectively. Evaluation of subjects' body pain diagrams did not demonstrate any spontaneous pain in the test areas (forearms). The clinical pain ratings of FM and LMP subjects remained unchanged after the experiments $(\mathrm{p}>.05)$, indicating that no lasting analgesia could be observed after termination of vibration.

\subsection{Sensitivity Adjusted Heat Pain Ratings (Baseline)}

Heat pulses, adjusted to each individual's pain sensitivity, were used as test stimuli at both forearms. After a series of repeated measures ANOVAs did not show statistically different pain ratings between forearm locations or forearms (all $\mathrm{p}>.05$ ), all heat pain ratings obtained during each condition were averaged for each subject. The stimulus temperatures necessary to achieve these ratings were 45.8 (2.3), 43.3 (2.4), and $44.7(2.6){ }^{\circ} \mathrm{C}$ for $\mathrm{NC}, \mathrm{FM}$, and LMP subjects, respectively. A one-way ANOVA demonstrated significant statistical differences between groups ( $\mathrm{p}$ <.001). Post-hoc tests using Duncan's procedure showed that significantly lower stimulus temperatures were necessary for FM subjects to achieve pain ratings of $4.0 \pm 0.5$ VAS units compared to NC and LMP subjects $(\mathrm{p}<.05)$. The average (SD) heat pain ratings of these adjusted test stimuli was 3.3 (1.1) for NC, 3.9 (1.1) for FM, 
and 4.0 (1.2) VAS units for LMP participants. A one-way ANOVA showed no statistical difference of these ratings between groups $(p>.05)$.

\subsection{Baseline Heat Pain Ratings}

Pain ratings of $10 \mathrm{~s}$ sensitivity adjusted heat pulses were obtained before and after each homotopic and heterotopic condition. The pain ratings of baseline heat pulse conditions were compared using a repeated measures ANOVA with time (3) as within and diagnosis (3) as between subjects factors. The average heat pain ratings were 3.77 (.65), 4.03 (1.1), and 4.13 (1.2) VAS units during baseline 1, baseline 2, and baseline 3, respectively. The ANOVA did not show significant main effects for time $\left(\mathrm{F}(2,72)=3.2 ; \mathrm{p}>.05 ;\right.$ part eta $^{2}=$. $08)$ or diagnosis $\left(\mathrm{F}(2,36)=1.2 ; \mathrm{p}>.05 ;\right.$ part eta $\left.^{2}=.007\right)$. The interaction effect of time $\mathrm{x}$ diagnosis was also non-significant $\left(\mathrm{F}(4,72)=.47 ; \mathrm{p}>.05\right.$; part eta $\left.^{2}=.03\right)$. After Kolomogorov-Smirnov tests of the dependent variables confirmed normal distribution of data (all $p>.05$ ) no data transformation was attempted to increase the sensitivity of the ANOVAs. These results demonstrated the stability of baseline heat pain ratings before and after vibro-tactile conditioning in all subjects.

\subsection{Vibro-Tactile Thresholds}

Because vibro-tactile thresholds of individual subjects did not differ between forearms ( $p>$. 05 ), these results were combined. Average (SD) vibration intensity at detection threshold was .012 (.006) m/s $\mathrm{s}^{2}$ for NC, .013 (.004) $\mathrm{m} / \mathrm{s}^{2}$ for FM, and .013 (.004) $\mathrm{m} / \mathrm{s}^{2}$ for LMP participants. A one-way ANOVA showed no difference of vibratory thresholds between groups $(\mathrm{F}(2,69)=1.0 ; \mathrm{p}>.05)$.

3.5.1.Homotopic Stimulation-When vibro-tactile stimuli were applied to the same forearms as test stimuli, heat pain ratings decreased from 3.4 (1.2) to 1.8 (1.1) in NC, from 3.8 (1.2) to 2.5 (1.4) in FM, and from 3.9 (1.3) to 2.4 (1.3) VAS units in LMP participants (Figure 1). A repeated measures ANOVA with time (2) as within and diagnostic group (3) as between subjects' factor showed significant main effects for time $(F(1,69)=142.2 ; \mathrm{p}<$. $001)$ and diagnostic group $(F(1,69)=3.2 ; p=.048)$. The significant main effect for time demonstrated that homotopic vibro-tactile stimulation were analgesic for study subjects. The interaction of diagnostic group $\mathrm{x}$ time, however, was not statistically significant $(\mathrm{F}(2,69)=$ $0.3 ; \mathrm{p}>.05$ ), indicating that pain reductions were not different between groups.

3.5.2 Heterotopic Stimulation-When vibro-tactile stimulations were used on forearms opposite to the test stimuli heat pain ratings decreased from 3.3 (1.1) to 2.1 (0.9) in NC, from 3.9 (1.1) to 2.9 (1.3) in FM, and from 4.0 (1.2) to 2.7 (1.2) VAS units in LMP participants (Figure 2). A repeated measures ANOVA with time (2) as within and diagnostic group (3) as between subjects' factor showed significant main effects for time $(\mathrm{F}(1,69)=$ $136.7 ; \mathrm{p}<.001)$ and diagnostic group $(\mathrm{F}(1,69)=3.2 ; \mathrm{p}=.046)$ demonstrating that experimental pain ratings significantly decreased during heterotopic stimulation The interaction of diagnostic group $\mathrm{x}$ time, however, was not statistically significant $(\mathrm{F}(2,69)=$ $2.1 ; p>.05)$, indicating that the pain reductions were not different between groups.

\subsubsection{Comparisons of Homotopic and Heterotopic Conditioning Effects-A} mixed model ANOVA was performed comparing the pain reductions associated with either homotopic or heterotopic stimulations. Within subjects factors were condition (2) and time (2) and between subjects' factor was diagnostic group (3). This analysis showed significant main effects for condition $(\mathrm{F}(1,69)=5.2 ; \mathrm{p}=.02)$, time $(\mathrm{F}(1,69)=170.8 ; \mathrm{p}<.001)$, and diagnostic group $(\mathrm{F}(1.69)=3.2 ; \mathrm{p}=.05)$. The interactions of diagnostic group $\mathrm{x}$ condition $\left(\mathrm{F}(2,69)=.03 ; \mathrm{p}>.05 ;\right.$ part $\left.\mathrm{eta}^{2}=.009\right)$ and diagnostic group $\mathrm{x}$ time $(\mathrm{F}(2,69)=.89 ; \mathrm{p}>.05$; part eta $^{2}=.025$ ) were not statistically significant. This analysis demonstrated greater 
analgesia during homotopic compared to heterotopic stimulation. The non-significant interaction effect of condition $\mathrm{x}$ diagnostic group, however, indicated that this effect was not different between diagnostic NC, FM, and LMP participants.

3.5.4 Effects of Distraction on Experimental Pain-Thirty-two of 72 study participants (44\%) stated that they felt distracted by vibro-tactile stimulation, i.e. their attentions had shifted away from the test stimuli during the heat pulses and focused on the vibro-tactile stimuli. The distraction ratings ( $0-10$ VAS) of these study participants were subsequently analyzed. The average (SD) rating of distraction magnitude was 3.4 (2.4) for NC, 4.3 (1.6) for FM, and 3.2 (1.8) for LMP participants. A one-way ANOVA showed no significantly different distraction ratings between groups $(\mathrm{p}>.05)$. A repeated measures ANOVA was performed to assess whether subjects using distraction differed in the magnitude of analgesia from those who did not. Within subjects' factors were vibro-tactile conditions (2) and time (2) and between subjects' factor was distraction (2). Similar to sections 3.5.1 and 3.5.2 this analysis showed significant main effects of condition $(\mathrm{p}<.01)$ and time $(\mathrm{p}<.001)$. However neither the interaction of condition $\mathrm{x}$ distraction $(\mathrm{F}(1,70)=.5$; $p>.05)$ nor the interaction of time $x$ distraction $(F(1,70)<.001 ; p>.05)$ were statistically significant indicating that pain ratings of individuals who felt distracted did not differ from those who remained focused on the test stimuli during homotopic and heterotopic conditioning alike.

\section{Discussion}

The results of our study demonstrate robust attenuation of experimental pain by either homotopic or heterotopic vibro-tactile stimulation in NC, FM, and LMP patients. The magnitude of endogenous analgesic effects was large (ca. $40 \%$ pain reductions) and not statistically different across all three subject groups. In our study, the analgesic effects of vibro-tactile stimulation were unlikely the result of distraction alone because a) less than half of all subjects reported distraction by vibro-tactile stimulation and b) the analgesic responsiveness of participants who reported distraction was not different from those who did not. Future studies will be necessary to explore the effects of distraction on vibro-tactile analgesia.

The analgesic effect of vibro-tactile stimuli was greater during homotopic compared to heterotopic conditioning stimulation ( $40 \%$ vs. $32 \%$ ) in all groups studied. Considerable neurophysiological evidence supports spinal segmental inhibition as an explanation for this effect (Salter and Henry 1990a; Salter and Henry 1990b). Such an analgesic mechanism had originally been envisioned by Melzack \& Wall in 1965 (Melzack and Wall 1965). Although not directly comparable, our current results differ considerably from several previous studies in FM and LMP patients which showed distinct deficits in analgesic mechanisms, including DNIC (Kosek and Hansson 1997; Lautenbacher and Rollman 1997; Arendt-Nielsen and Bjerring 1988; Kosek and Ordeberg 2000; Sandrini et al., 2006), spatial summation (Julien et al., 2005), and pain habituation (Montoya et al., 2006; Smith et al., 2008). Other investigations, however, have provided evidence for at least some types of functional analgesic mechanisms in FM patients (Staud et al., 2007; Staud et al., 2004b; Staud et al., 2010). This suggests that not all analgesic mechanisms are uniformly or greatly compromised in FM and other types of chronic pain patients. Overall, vibro-tactile stimulation appears to reliably activate analgesic mechanisms in chronic musculoskeletal pain patients which can powerfully inhibit experimental pain. 


\subsection{Analgesic Mechanisms of Vibro-Tactile Analgesia}

A major component of vibro-tactile analgesia is likely related to A-beta mediated afferent inhibition of dorsal horn nociceptive neurons (Salter and Henry 1990a; Salter and Henry 1990b). In both anesthetized and decerebrate cats high frequency vibro-tactile stimulation of large diameter low threshold mechanoreceptive afferents has been found to inhibit responses of nociceptive dorsal horn neurons to noxious stimuli and to local iontophoretic application of glutamate (Salter and Henry 1990a). Another component of central modulation of peripheral noxious input by vibro-tactile stimulation may reflect interactions that seem to occur between different divisions of the somato-sensory cortex (S1). Using optical intrinsic signal imaging, Tommerdahl and Whitsel have shown that cutaneous vibro-tactile stimuli result in frequency-dependent reduction in cortical responsiveness to heat nociceptive input. (Whitsel et al., 1999; Tommerdahl et al., 1999b). In contrast to $25 \mathrm{~Hz}$ skin stimulation which does not seem to change $\mathrm{S} 1$ activation, vibro-tactile stimulation frequencies, similar to those used in the present study $(100 \mathrm{~Hz})$, resulted in potent suppression/inhibition of heat nociceptive responses within S1 (Tommerdahl et al., 1999a; Whitsel et al., 2000). However, the interactions found within S-1 may at least partly reflect consequences of spinal segmental mechanisms because no evidence has ruled them out.

Similar to vibro-tactile stimulation, analgesia from high frequency - low intensity transcutaneous electrical nerve stimulation (TENS) also appears to be dependent on large diameter fiber cutaneous input into the dorsal horn (Sluka and Walsh 2003). Several studies emphasized segmentally mediated inhibition mechanisms in TENS analgesia (Woolf et al., 1980). The important role of spinal inhibitory mechanisms was best illustrated by high frequency stimulation TENS experiments which resulted in dorsal horn neuron inhibition (Garrison and Foreman 1994). However, transection of the spinal cord which removes descending inhibitory influences only partially prevented this effect (Garrison and Foreman 1996). On the other hand, low frequency-high intensity TENS may activate local spinal mechanisms as well as descending control mechanisms (Sluka and Walsh 2003).

\subsection{Effects of Intense Heterotopic Stimulation ("Diffuse Noxious Inhibitory Controls")}

In contrast to vibro-tactile analgesia and low intensity - high frequency TENS which strongly depend on A-beta fiber mediated dorsal horn inhibitory mechanisms, intense heterotopic stimulation, also called diffuse noxious inhibitory controls (DNIC) or conditioned pain modulation (CPM) (Yarnitsky et al., 2010), produces analgesia by inhibition of dorsal horn nociceptive neurons mostly through descending anti-nociceptive modulation (Le Bars et al., 1979; Le Bars 2002). Recent evidence indicates that patients with idiopathic pain disorders, such as temporo-mandibular disorders, FM, tension headache, migraine and irritable bowel syndrome, demonstrate lower DNIC efficiency compared to NC (Julien et al., 2005; Maixner et al., 1995; Pielsticker et al., 2005). Similarly, less efficient DNIC has been associated with an extended history of pain among healthy subjects (Edwards et al., 2003). However, DNIC efficiency does not seem to predict chronic post-operative pain (Yarnitsky et al., 2008) suggesting that altered analgesic mechanisms might be relevant in the pathogenesis of idiopathic pain disorders but not for chronic postoperative pain. Furthermore, the strength of this form of inhibition seems to decline not only in patients with chronic pain disorders but also with age (Edwards and Fillingim 2001; Washington et al., 2000). DNIC appears to progressively decrease across the adult lifespan beginning by middle age (Lariviere et al., 2007). However, it is important to note that age effects on DNIC strength were appreciable only at the highest tolerated test temperatures.

\subsection{Testing of Endogenous Analgesic Mechanisms}

Endogenous analgesic mechanisms are particularly relevant for post-traumatic or postsurgical pain. Only few studies have explored the predictive value of pain-modulatory 
psychophysical assessments for such circumstances, often providing mixed results (Granot et al., 2003; Hsu et al., 2005; Nielsen et al., 2007; Pan et al., 2006). Although some reports showed good correlations of baseline pain thresholds with acute post-traumatic pain ratings (Nielsen et al., 2007; Pan et al., 2006; Strulov et al., 2007; Werner et al., 2004), others did not (Granot et al., 2003; Hsu et al., 2005; Wilder-Smith et al., 2003; Yarnitsky et al., 2008). Similar findings were obtained with psychophysical tests using supra-threshold noxious stimuli (Bisgaard et al., 2001; Granot et al., 2003; Hsu et al., 2005; Wilder-Smith et al., 2003; Yarnitsky et al., 2008). At least some discrepancies between the results of these studies may be related to experimental designs (Yarnitsky 2010).

In contrast to DNIC, tests of pain reduction by vibro-tactile stimulation reflect a very different type of somatosensory analgesic mechanism in NC and chronic pain patients. Overall, tests avoiding high intensity A-delta and C-fiber stimulation, like our vibro-tactile method, show that at least some types of pain-inhibitory mechanisms are not compromised in FM and LMP patients. Other functional analgesic mechanisms include normal analgesic responses to placebo (Staud et al., 2009; Wandel et al., 2010) and intravenous opioids (Price et al., 2002; Furlan et al., 2006). Overall, vibro-tactile stimulation tests appear to be well tolerated by study participants and well suited for characterizing not only pain modulatory capacities of $\mathrm{NC}$ but also of individuals with chronic pain.

\section{Conclusion}

Pain modulatory deficits of CWP and LMP patients have been mostly detected using highly noxious conditioning stimuli that preferentially activate nociceptive afferent neurons (Adelta and $\mathrm{C}$ nociceptive afferents). In contrast, pain modulatory deficiencies of chronic pain patients have often been absent when innocuous stimuli were utilized, as in our study. These findings suggest that deficiencies of endogenous analgesic mechanisms in CWP and LMP patients are restricted to specific types of pain modulation and not to all forms of endogenous analgesia. Thus future studies of analgesic mechanisms in CWP and other chronic patients should include tests that assess multiple types of pain modulation. Given the potent effects observed in the present study, clinical investigations of analgesia using vibrotactile stimulation in various musculoskeletal pain disorders, including FM and LMP, seem warranted.

\section{Acknowledgments}

This work was supported by NIH grants NS041670 and AR053541. None of the authors has any conflicts of interest. The expert technical assistance of Amber M. Schwier, Elena M. Moran, and Elizabeth E. Weyl is greatly appreciated.

\section{Reference List}

Arendt-Nielsen L, Bjerring P. Laser-induced pain for evaluation of local analgesia: a comparison of topical application (EMLA) and local injection (lidocaine). Anesth Analg. 1988; 67(2):115-23. [PubMed: 3341564]

Arendt-Nielsen L, Nie HL, Laursen MB, Laursen BS, Madeleine P, Simonsen OH, Graven-Nielsen T. Sensitization in patients with painful knee osteoarthritis. Pain. 2010; 149(3):573-81. [PubMed: 20418016]

Bisgaard T, Klarskov B, Rosenberg J, Kehlet H. Characteristics and prediction of early pain after laparoscopic cholecystectomy. Pain. 2001; 90(3):261-9. [PubMed: 11207398]

Butler RK, Finn DP. Stress-induced analgesia. Prog Neurobiol. 2009; 88(3):184-202. [PubMed: 19393288] 
Carlton SM, Zhou ST, Du JH, Hargett GL, Ji GC, Coggeshall RE. Somatostatin modulates the transient receptor potential vanilloid 1 (TRPV1) ion channel. Pain. 2004; 110(3):616-27. [PubMed: 15288402]

Clauw DJ. The pathogenesis of chronic pain and fatigue syndromes, with special reference to fibromyalgia. Med Hypotheses. 1995; 44(5):369-78. [PubMed: 8583967]

de Souza JB, Potvin S, Goffaux P, Charest J, Marchand S. The deficit of pain inhibition in fibromyalgia is more pronounced in patients with comorbid depressive symptoms. Clin J Pain. 2009; 25(2):123-7. [PubMed: 19333157]

Desmeules JA, Cedraschi C, Rapiti E, Baumgartner E, Finckh A, Cohen P, Dayer P, Vischer TL. Neurophysiologic evidence for a central sensitization in patients with fibromyalgia. Arthritis Rheum. 2003; 48(5):1420-9. [PubMed: 12746916]

Edwards RR, Fillingim RB. Age-associated differences in responses to noxious stimuli. J Gerontol A Biol Sci Med Sci. 2001; 56(3):M180-M185. [PubMed: 11253160]

Edwards RR, Ness TJ, Weigent DA, Fillingim RB. Individual differences in diffuse noxious inhibitory controls (DNIC): association with clinical variables. Pain. 2003; 106(3):427-37. [PubMed: 14659526]

Furlan AD, Sandoval JA, Mailis-Gagnon A, Tunks E. Opioids for chronic noncancer pain: a metaanalysis of effectiveness and side effects. Canadian Medical Association Journal. 2006; 174(11): 1589-94. [PubMed: 16717269]

Garrison DW, Foreman RD. Decreased activity of spontaneous and noxiously evoked dorsal horn cells during transcutaneous electrical nerve stimulation (TENS). Pain. 1994; 58(3):309-15. [PubMed: 7838579]

Garrison DW, Foreman RD. Effects of transcutaneous electrical nerve stimulation (TENS) on spontaneous and noxiously evoked dorsal horn cell activity in cats with transected spinal cords. Neurosci Lett. 1996; 216(2):125-8. [PubMed: 8904799]

Giovengo SL, Russell IJ, Larson AA. Increased concentrations of nerve growth factor in cerebrospinal fluid of patients with fibromyalgia. J Rheumatol. 1999; 26(7):1564-9. [PubMed: 10405946]

Granot M, Lowenstein L, Yarnitsky D, Tamir A, Zimmer EZ. Postcesarean section pain prediction by preoperative experimental pain assessment. Anesthesiology. 2003; 98(6):1422-6. [PubMed: 12766652]

Hsu YW, Somma J, Hung YC, Tsai PS, Yang CH, Chen CC. Predicting postoperative pain by preoperative pressure pain assessment. Anesthesiology. 2005; 103(3):613-8. [PubMed: 16129988]

Julien N, Goffaux P, Arsenault P, Marchand S. Widespread pain in fibromyalgia is related to a deficit of endogenous pain inhibition. Pain. 2005; 114(1-2):295-302. [PubMed: 15733656]

Kosek E, Hansson P. Modulatory influence on somatosensory perception from vibration and heterotopic noxious conditioning stimulation (HNCS) in fibromyalgia patients and healthy subjects. Pain. 1997; 70(1):41-51. [PubMed: 9106808]

Kosek E, Ordeberg G. Lack of pressure pain modulation by heterotopic noxious conditioning stimulation in patients with painful osteoarthritis before, but not following, surgical pain relief. Pain. 2000; 88(1):69-78. [PubMed: 11098101]

Lariviere M, Goffaux P, Marchand S, Julien N. Changes in pain perception and descending inhibitory controls start at middle age in healthy adults. Clin J Pain. 2007; 23(6):506-10. [PubMed: 17575490]

Lautenbacher S, Kunz M, Burkhardt S. The effects of DNIC-type inhibition on temporal summation compared to single pulse processing: Does sex matter? Pain. 2008; 140(3):429-35. [PubMed: 18950941]

Lautenbacher S, Rollman GB. Possible deficiencies of pain modulation in fibromyalgia. Clin J Pain. 1997; 13(3):189-96. [PubMed: 9303250]

Le Bars D. The whole body receptive field of dorsal horn multireceptive neurones. Brain Res Rev. 2002; 40(1-3):29-44. [PubMed: 12589904]

Le Bars D, Dickenson AH, Besson JM. Diffuse noxious inhibitory controls (DNIC). I. Effects on dorsal horn convergent neurones in the rat. Pain. 1979; 6(3):283-304. [PubMed: 460935] 
Maixner W, Fillingim R, Booker D, Sigurdsson A. Sensitivity of patients with painful temporomandibular disorders to experimentally evoked pain. Pain. 1995; 63(3):341-51. [PubMed: 8719535]

Melzack R, Wall PD. Pain mechanisms: A new theory. Science. 1965; 150:971-9. [PubMed: 5320816]

Montoya P, Sitges C, Garcia-Herrera M, Rodriguez-Cotes A, Izquierdo R, Truyols M, Collado D. Reduced brain habituation to somatosensory stimulation in patients with fibromyalgia. Arthritis Rheum. 2006; 54(6):1995-2003. [PubMed: 16732548]

Nielsen PR, Norgaard L, Rasmussen LS, Kehlet H. Prediction of post-operative pain by an electrical pain stimulus. Acta Anaesthesiol Scand. 2007; 51:582-6. [PubMed: 17430320]

Pan PH, Coghill R, Houle TT, Seid MH, Lindel WM, Parker RL, Washburn SA, Harris L, Eisenach JC. Multifactorial preoperative predictors for postcesarean section pain and analgesic requirement. Anesthesiology. 2006; 104(3):417-25. [PubMed: 16508387]

Peltz E, Seifert F, Decol R, Dorfler A, Schwab S, Maihofner C. Functional connectivity of the human insular cortex during noxious and innocuous thermal stimulation. Neuroimage. 2011; 54(2):132435. [PubMed: 20851770]

Pielsticker A, Haag G, Zaudig M, Lautenbacher S. Impairment of pain inhibition in chronic tensiontype headache. Pain. 2005; 118(1-2):215-23. [PubMed: 16202520]

Price DD, Bush FM, Long S, Harkins SW. A comparison of pain measurement characteristics of mechanical visual analogue and simple numerical rating scales. Pain. 1994; 56(2):217-26. [PubMed: 8008411]

Price, DD.; Harkins, SW. Psychophysical approaches to pain measurement and assessment. In: Turk, DC.; Melzack, R., editors. Handbook of Pain Assessment. Vol. 1. New York: Guilford Press; 1992. p. 114-134.

Price DD, Staud R, Robinson ME, Mauderli AP, Cannon RL, Vierck CJ. Enhanced temporal summation of second pain and its central modulation in fibromyalgia patients. Pain. 2002; 99:4959. [PubMed: 12237183]

Russell IJ, Orr MD, Littman B, Vipraio GA, Alboukrek D, Michalek JE, Lopez Y, MacKillip F. Elevated cerebrospinal fluid levels of substance $\mathrm{P}$ in patients with the fibromyalgia syndrome. Arthritis Rheum. 1994; 37(11):1593-601. [PubMed: 7526868]

Russell IJ, Vaeroy H, Javors M, Nyberg F. Cerebrospinal fluid biogenic amine metabolites in fibromyalgia/fibrositis syndrome and rheumatoid arthritis. Arthritis Rheum. 1992; 35(5):550-6. [PubMed: 1374252]

Salter MW, Henry JL. Differential responses of nociceptive vs. non-nociceptive spinal dorsal horn neurones to cutaneously applied vibration in the cat. Pain. 1990a; 40(3):311-22. [PubMed: 2326096]

Salter MW, Henry JL. Physiological characteristics of responses of wide dynamic range spinal neurones to cutaneously applied vibration in the cat. Brain Res. 1990b; 507(1):69-84. [PubMed: 2302582]

Sandrini G, Rossi P, Milanov I, Serrao M, Cecchini AP, Nappi G. Abnormal modulatory influence of diffuse noxious inhibitory controls in migraine and chronic tension-type headache patients. Cephalalgia. 2006; 26(7):782-9. [PubMed: 16776692]

Sluka KA, Walsh D. Transcutaneous electrical nerve stimulation: basic science mechanisms and clinical effectiveness. J Pain. 2003; 4(3):109-21. [PubMed: 14622708]

Smith BW, Tooley EM, Montague EQ, Robinson AE, Cosper CJ, Mullins PG. Habituation and sensitization to heat and cold pain in women with fibromyalgia and healthy controls. Pain. 2008; 140(3):420-8. [PubMed: 18947923]

Staud R. Abnormal pain modulation in patients with spatially distributed chronic pain: Fibromyalgia. Rheum Dis Clin North Am. 2009; 35(2):263-74. [PubMed: 19647141]

Staud R, Koo E, Robinson ME, Price DD. Spatial summation of mechanically evoked muscle pain and painful aftersensations in normal subject and fibromyalgia patients. Pain. 2007; 130(1-2):177-87. [PubMed: 17459587]

Staud R, Nagel S, Robinson ME, Price DD. Enhanced central pain processing of fibromyalgia patients is maintained by muscle afferent input: a randomized, double-blind, placebo controlled trial. Pain. 2009; 145:96-104. [PubMed: 19540671] 
Staud R, Price DD, Robinson ME, Vierck CJ. Body pain area and pain-related negative affect predict clinical pain intensity in patients with fibromyalgia. J Pain. 2004a; 5(6):338-43. [PubMed: 15336638]

Staud R, Robinson ME, Vierck CJ, Price DD. Diffuse noxious inhibitory controls (DNIC) attenuate temporal summation of second pain in normal males but not in normal females or fibromyalgia patients. Pain. 2003; 101:167-74. [PubMed: 12507711]

Staud R, Robinson ME, Weyl EE, Price DD. Pain Variability in Fibromyalgia Is Related to Activity and Rest: Role of Peripheral Tissue Impulse Input. J Pain. 2010; 11(12):1376-83. [PubMed: 20451465]

Staud R, Vierck CJ, Robinson ME, Price DD. Spatial summation of heat pain within and across dermatomes in fibromyalgia patients and pain-free subjects. Pain. 2004b; 111(3):342-50. [PubMed: 15363878]

Strulov L, Zimmer EZ, Granot M, Tamir A, Jakobi P, Lowenstein L. Pain catastrophizing, response to experimental heat stimuli, and post-cesarean section pain. J Pain. 2007; 8(3):273-9. [PubMed: 17113350]

Tommerdahl M, Delemos KA, Whitsel BL, Favorov OV, Metz CB. Response of anterior parietal cortex to cutaneous flutter versus vibration. J Neurophysiol. 1999a; 82(1):16-33. [PubMed: 10400931]

Tommerdahl M, Favorov OV, Whitsel BL. Effects of high-frequency skin stimulation on SI cortex: mechanisms and functional implications. Somatosens Mot Res. 2005; 22(3):151-69. [PubMed: 16338824]

Tommerdahl M, Whitsel BL, Favorov OV, Metz CB, O'Quinn BL. Responses of contralateral SI and SII in cat to same-site cutaneous flutter versus vibration. J Neurophysiol. 1999b; 82(4):1982-92. [PubMed: 10515988]

Vaeroy H, Helle R, Forre O, Kass E, Terenius L. Elevated CSF levels of substance P and high incidence of Raynaud phenomenon in patients with fibromyalgia: new features for diagnosis. Pain. 1988; 32(1):21-6. [PubMed: 2448729]

Vierck CJ Jr. Mechanisms underlying development of spatially distributed chronic pain (fibromyalgia). Pain. 2006; 124(3):242-63. [PubMed: 16842915]

Wandel S, Juni P, Tendal B, Nuesch E, Villiger PM, Welton NJ, Reichenbach S, Trelle S. Effects of glucosamine, chondroitin, or placebo in patients with osteoarthritis of hip or knee: network metaanalysis. BMJ. 2010; 341:c4675. [PubMed: 20847017]

Washington LL, Gibson SJ, Helme RD. Age-related differences in the endogenous analgesic response to repeated cold water immersion in human volunteers. Pain. 2000; 89(1):89-96. [PubMed: 11113297]

Werner MU, Duun P, Kehlet H. Prediction of postoperative pain by preoperative nociceptive reponses to heat stimulation. Anesthesiology. 2004; 100(1):115-9. [PubMed: 14695732]

Whitsel BL, Favorov O, Delemos KA, Lee C, Tommerdahl M, Essick GK, Nakhle B. SI neuron response variability is stimulus tuned and NMDA receptor dependent. J Neurophysiol. 1999; 81(6):2988-3006. [PubMed: 10368415]

Whitsel, BL.; Tommerdahl, M.; Kohn, A.; Vierck, CJ.; Favorov, O. The S1 response to noxious skin heating by optical intrinsic signal imaging. In: Casey, KL.; Bushnell, MC., editors. Pain Imaging, Progress in Pain Research and Managment. Seattle: IASP Press; 2000. p. 47-93.

Wilder-Smith OHG, Tassonyi E, Crul BJP, Arendt-Nielsen L. Quantitative sensory testing and human surgery - Effects of analgesic management on postoperative neuroplasticity. Anesthesiology. 2003; 98(5):1214-22. [PubMed: 12717144]

Wolfe F. Fibromyalgia. Rheum Dis Clin North Am. 1990; 16(3):681-98. [PubMed: 2217965]

Wolfe F, Smythe HA, Yunus MB, Bennett RM, Bombardier C, Goldenberg DL, Tugwell P, Campbell SM, Abeles M, Clark P, Fam AG, Farber SJ, Fiechtner JJ, Franklin CM, Gatter RA, Hamaty D, Lessard J, Lichtbroun AS, Masi AT, McCain GA, Reynolds WJ, Romano TJ, Russell IJ, Sheon RP. The American College of Rheumatology 1990 Criteria for the Classification of Fibromyalgia. Report of the Multicenter Criteria Committee. Arthritis Rheum. 1990; 33(2):160-72. [PubMed: 2306288] 
Woolf CJ, Mitchell D, Barrett GD. Antinociceptive effect of peripheral segmental electrical stimulation in the rat. Pain. 1980; 8(2):237-52. [PubMed: 7402687]

Yarnitsky D. Conditioned pain modulation (the diffuse noxious inhibitory control-like effect): its relevance for acute and chronic pain states. Curr Opin Anaesthesiol. 2010; 23(5):611-5. [PubMed: 20543676]

Yarnitsky D, Arendt-Nielsen L, Bouhassira D, Edwards RR, Fillingim RB, Granot M, Hansson P, Lautenbacher S, Marchand S, Wilder-Smith O. Recommendations on terminology and practice of psychophysical DNIC testing. Eur J Pain. 2010; 14(4):339. [PubMed: 20227310]

Yarnitsky D, Crispel Y, Eisenberg E, Granovsky Y, Ben-Nun A, Sprecher E, Best LA, Granot M. Prediction of chronic post-operative pain: Pre-operative DNIC testing identifies patients at risk. Pain. 2008; 138(1):22-8. [PubMed: 18079062] 


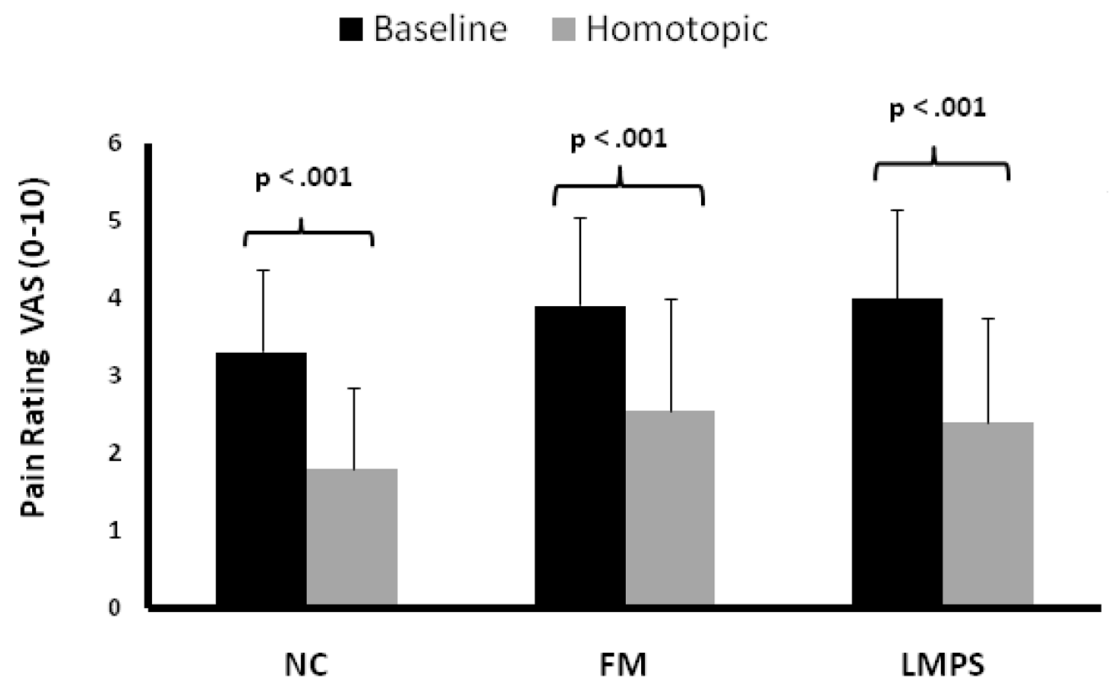

Figure 1.

Average (SD) heat pain ratings during $10 \mathrm{~s}$ of sensitivity adjusted heat pulses to the forearms of NC, FM, and LMP subjects (Baseline). Statistically significant reductions of experimental pain intensities were observed during homotopic vibro-tactile stimulations in all study participants. There were, however, no significant differences of vibration dependent pain reductions between groups $(\mathrm{p}>.05)$. $\mathrm{NC}=$ normal controls; $\mathrm{FM}=$ fibromyalgia; $\mathrm{LMP}=$ patients with localized musculoskeletal pain 


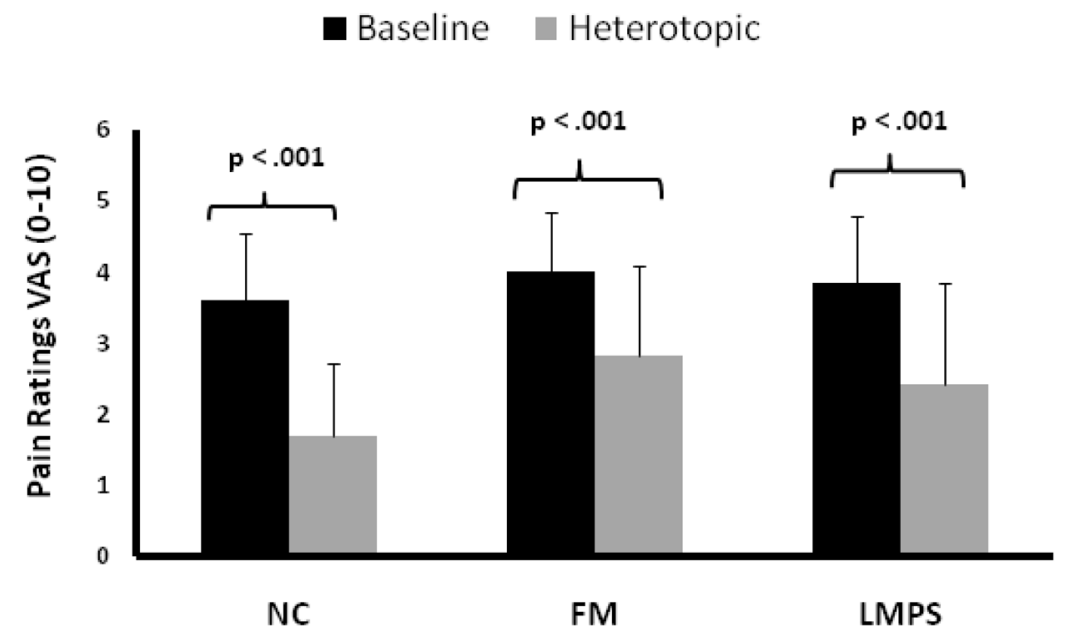

Figure 2.

Average (SD) heat pain ratings during $10 \mathrm{~s}$ of sensitivity adjusted heat pulses to the forearms of NC, FM, and LMP subjects (Baseline). Statistically significant reductions of experimental pain intensities were observed during heterotopic vibro-tactile stimulations in all study participants $(\mathrm{p}<.001)$. There were, however, no significant differences of vibration dependent pain reductions between groups $(\mathrm{p}>.05)$. $\mathrm{NC}=$ normal controls; $\mathrm{FM}=$ fibromyalgia; LMP = patients with localized musculoskeletal pain 